\title{
Identification of the Impacts of Climate Changes and Human Activities on Runoff in the Jinsha River Basin, China
}

\author{
Xiaowan Liu, Dingzhi Peng, and Zongxue Xu \\ College of Water Sciences, Beijing Normal University, Beijing 100875, China \\ Correspondence should be addressed to Dingzhi Peng; dzpeng@bnu.edu.cn \\ Received 30 March 2017; Revised 28 May 2017; Accepted 6 June 2017; Published 20 July 2017 \\ Academic Editor: Mario M. Miglietta \\ Copyright (C) 2017 Xiaowan Liu et al. This is an open access article distributed under the Creative Commons Attribution License, \\ which permits unrestricted use, distribution, and reproduction in any medium, provided the original work is properly cited.

\begin{abstract}
Quantifying the impacts of climate changes and human activities on runoff has received extensive attention, especially for the regions with significant elevation difference. The contributions of climate changes and human activities to runoff were analyzed using rainfall-runoff relationship, double mass curve, slope variation, and water balance method during 1961-2010 at the Jinsha River basin, China. Results indicate that runoff at upstream and runoff at midstream are both dominated by climate changes, and the contributions of climate changes to runoff are $63 \% \sim 72 \%$ and $53 \% \sim 68 \%$, respectively. At downstream, climate changes account for only $13 \% \sim 18 \%$, and runoff is mainly controlled by human activities, contributing $82 \% \sim 87 \%$. The availability and stability of results were compared and analyzed in the four methods. Results in slope variation, double mass curve, and water balance method except rainfall-runoff relationship method are of good agreement. And the rainfall-runoff relationship, double mass curve, and slope variation method are all of great stability. The four methods and availability evaluation of them could provide a reference to quantification in the contributions of climate changes and human activities to runoff at similar basins in the future.
\end{abstract}

\section{Introduction}

Flood and drought are increasing with frequency, which can primarily be attributed to climate changes and human activities [1-3]. Global warming becomes an unchangeable truth and may cause a series of consequences as precipitation pattern change and evaporation alternates, which may cause direct and dramatic effects on runoff [4-8].

Exploring runoff responses to climate changes and human activities has become a hot topic due to dramatic global warming and intensive urbanization. However, the great uncertainties of human activities and the scarcity of available data determine the difficulty in understanding runoff responses to climate changes and human activities $[9,10]$. At present, an increasing number of studies have investigated the contributions of climate changes and human activities to runoff using hydrological modeling and statistical methods [11-16]. First, hydrological modeling is followed by calibrating the model parameters on the basis of previous available field data and later projecting runoff variations under the assumption of different future scenarios. Even though a great amount of remote sensing data with higher spatial and temporary resolution has become available for use, uncertainties with climate variability are still unavoidable [17]. Moreover, parameter calibration in the process of model construction and the lack of knowledge in model structure are also derivations of the uncertainties within outputs, and the lack of high-accuracy data is another important reason for modeling work to be limited [18, 19]. Several statistical methods were developed and widely applied, such as the rainfall-runoff relationship [20], slope variation [21], double mass curve $[22,23]$, and water balance method $[16,20]$. However, studies in high elevation-difference regions and comparative analysis of methods are still lacking [24].

As the upper reaches of the Yangtze River, Jinsha River basin was chosen as a case study. The four methods (rainfallrunoff relationship, double mass curve, slope variation, and water balance method) were applied to identify the impacts of climate changes and human activities on runoff, and their performance was also evaluated. The quantification of contributions of climate change and human activities on runoff would be helpful to understand runoff response under changing environment. 


\section{Methodology}

2.1. Rainfall-Runoff Relationship Method. The rainfall-runoff relationship method is the earliest and simplest method to quantify the contribution of climate changes to runoff by using change-point identification and division of change period [25]. The contribution of climate changes to runoff was obtained by establishing relationship between precipitation and runoff in the method. The relationship of runoff $(Q)$ and rainfall $(P)$ could be described as follows:

$$
Q=a+b \times P \times \sigma^{c}
$$

where $\sigma$ is the variance of $P ; a, b$, and $c$ are parameters obtained by the least square method [26]. The calibration procedure of the method is listed as follows:

(a) The change point of measured annual runoff was identified by slide $t$-test [16]. The study period was divided into two parts (baseline period and change period) by the change point.

(b) The contribution of human activities to runoff $\left(C_{H}\right)$ could be calculated as follows:

$$
C_{H}=\frac{\left(\overline{\widehat{Q}}_{B}-\bar{Q}_{B}\right) / \bar{Q}_{B}}{\left(\bar{Q}_{B}-\bar{Q}_{A}\right) / \bar{Q}_{A}},
$$

where $A$ and $B$ represent baseline period and change period, respectively. $\overline{\widehat{Q}}_{B}$ is the mean simulated runoff in the change period by using the relationship defined in the baseline period. And $\bar{Q}_{B}$ is the mean measured runoff in the change period. $\bar{Q}_{A}$ represents the mean measured runoff in the baseline period.

(c) The contribution of climate changes $\left(C_{C}\right)$ is then computed as follows:

$$
C_{C}=1-C_{H}
$$

2.2. Slope Variation Method. Similar to the rainfall-runoff relationship method, the change-point identification is also needed in the slope variation method [21]. The effect of climate change is decomposed into precipitation and actual evapotranspiration, which are quantified by a slope variation comparison. The specific procedure can be described as the following steps:

(a) Determine the change point in cumulative runoff, precipitation, and evaporation, which divides the study period into two parts (baseline period and change period, that is, $A$ and $B$ ).

(b) Calculate slopes of cumulative runoff, precipitation, and evaporation in baseline period and change period, which were marked as $k_{\mathrm{QA}}, k_{\mathrm{QB}}, k_{P A}, k_{P B}$, $k_{E A}, k_{E B}$, respectively. Then, slope variability could be calculated:

$$
\begin{aligned}
& S_{\mathrm{Q}}=\frac{\left(k_{\mathrm{QB}}-k_{\mathrm{QA}}\right)}{k_{\mathrm{QA}}}, \\
& S_{P}=\frac{\left(k_{P B}-k_{P A}\right)}{k_{P A}},
\end{aligned}
$$

$$
S_{E}=\frac{\left(k_{E B}-k_{E A}\right)}{k_{E A}},
$$

where $S_{Q}, S_{P}$, and $S_{E}$ are slope variability for cumulative runoff, precipitation, and evaporation, respectively.

(c) The contributions of precipitation $\left(C_{P}\right)$ and evaporation $\left(C_{E}\right)$ to runoff are listed as follows:

$$
\begin{gathered}
C_{P}=\frac{S_{P}}{S_{Q}}, \\
C_{E}=\frac{S_{E}}{S_{Q}} .
\end{gathered}
$$

The contribution of climate changes is

$$
C_{C}=C_{P}+C_{E} \text {. }
$$

(d) The contribution of human activities could be calculated:

$$
C_{H}=1-C_{C}
$$

2.3. Double Mass Curve Method. Similar to the previous two methods, the double mass curve method is also based on the change-point identification to divide the study period into two parts (baseline period and change period). In the method, the relationship of cumulative runoff and cumulative precipitation and evapotranspiration was built. The main procedure is listed as follows:

(a) Determine the change point to divide the study period into baseline period and change period like the previous two methods.

(b) The linear relationship between cumulative runoff, cumulative precipitation, and cumulative potential evapotranspiration in the baseline period was established as

$$
\sum Q=k_{1} \sum P+k_{2} \sum E_{T}+k_{3},
$$

where $E_{T}$ refers to potential evapotranspiration. $k_{1}$, $k_{2}$, and $k_{3}$ are parameters. The cumulative runoff in the change period was calculated using the linear relationship defined in the baseline period.

(c) The runoff variation $\Delta Q$ is

$$
\Delta Q=\bar{Q}_{B}-\bar{Q}_{A} \text {. }
$$

(d) The variation induced by human activities $\Delta Q_{H}$ is

$$
\Delta Q_{H}=\overline{\mathrm{Q}}_{B}-\bar{Q}_{B} .
$$

(e) The contribution of human activities could be calculated:

$$
C_{H}=\frac{\Delta Q_{H}}{\Delta Q}
$$

The contribution of climate changes is

$$
C_{C}=1-C_{H} .
$$


TABLE 1: Contributions of climate change and human activities to runoff by rainfall-runoff relationship method.

\begin{tabular}{lccc}
\hline \multirow{2}{*}{ Divisions } & \multicolumn{2}{c}{ Contributions (\%) } & Relationship between $Q$ and $P$ \\
\hline I & Climate changes & Human activities & $R^{2}$ \\
II & 46 & 54 & $Q=162.9+8.659 \times P \times \sigma^{-0.7428}$ \\
III & 38 & 62 & $Q=20.99+11.41 \times P \times \sigma^{-0.4863}$ \\
\hline
\end{tabular}

Note. $R^{2}$ is the coefficient of determination.

2.4. Water Balance Method. The water balance in a basin is described as

$$
P=E+Q+\Delta S
$$

where $E$ is evapotranspiration and $\Delta S$ is the variation of water storage in the basin, which is considered to be zero over a long period of time, such as 5-10 years [16]. The long-term annual evapotranspiration could be calculated as [27]

$$
\frac{E}{P}=\frac{1+w\left(E_{T} / P\right)}{1+w\left(E_{T} / P\right)+\left(E_{T} / P\right)^{-1}}
$$

where $w$ is a parameter relating to vegetation types. The relationship between runoff, precipitation, and potential evapotranspiration changes is defined as [28]

$$
\Delta Q_{C}=\beta \Delta P+\gamma \Delta E_{T},
$$

where $\Delta Q_{C}$ describes the variation of runoff induced by climate changes. $\Delta P$ and $\Delta E_{T}$ are the variations of precipitation and potential evapotranspiration, respectively. $\beta$ is the sensitivity coefficient of runoff to precipitation, and $\gamma$ is the sensitivity coefficient to potential evapotranspiration. The two parameters $(\beta$ and $\gamma)$ can be calculated by

$$
\begin{aligned}
& \beta=\frac{1+2 z+3 w z}{\left(1+z+w z^{2}\right)^{2}}, \\
& \gamma=-\frac{1+2 w z}{\left(1+z+w z^{2}\right)^{2}},
\end{aligned}
$$

where $z$ is a dryness index $\left(E_{T} / P\right)$. In addition, $\omega$ is a parameter to reflect vegetation and soil conditions in the study area and equals 2.0 in this study with the proposal given by Liu and Zhang [29].

\section{Case Study}

3.1. Study Area. The Jinsha River basin (Figure 1) is located in the upstream of the Yangtze River basin. As the most important economic center in China, Yangtze River basin holds approximately $30 \%$ of population of the country. The Jinsha River basin covers an area of $3.4 \times 10^{5} \mathrm{~km}^{2}$ with a total length of $2316 \mathrm{~m}$, and it plays a significant role in water supply and ecological barriers for the Yangtze River basin. The Jinsha River basin is also characterized by the significant elevation difference of $5231 \mathrm{~m}$. According to elevation, the basin could be divided into three parts (I: above $4000 \mathrm{~m}$, II:
3000 4000 m, and III: below $3000 \mathrm{~m}$ ). The source of water vapor over the basin mainly includes the Bay of Bengal, the South China Sea, and the Western Pacific [30]. The areal mean annual precipitation in I, II, and III regions is $344 \mathrm{~mm}$, $614 \mathrm{~mm}$, and $900 \mathrm{~mm}$, respectively.

3.2. Data. The daily precipitation and evaporation data (1961-2010) about 25 meteorological stations in the basin was downloaded from the China Meteorological Data Service Center (http://data.cma.cn/) (Figure 1). The daily streamflow data at Zhimenda (upstream), Shigu (midstream), and Pingshan (downstream) was obtained from the Hydrology Bureau, Changjiang Water Resources Commission. The Digital Elevation Model (DEM) data with $90 \mathrm{~m}$ resolution was downloaded from the Consortium for Spatial Information (CGIAR-CSI).

The potential evapotranspiration was estimated by equations introduced by $\mathrm{Li}$ et al. [31]. The areal mean annual precipitation and potential evapotranspiration of I, II, and III region were used by interpolating the data of relevant 25 meteorological stations with the Inverse Distance Weighted (IDW) method. Zhimenda, Shigu, and Pingshan are regarded as outlets of the I, II, and III regions, respectively. To quantify the contributions of climate changes and human activities to runoff, rainfall-runoff relationship method, slope variation method, double mass curve method, and water balance method were employed in the study. And the annual data of rainfall and runoff during 1961 2010 was used.

\section{Results}

Identifying the change point in streamflow, precipitation, actual and potential evapotranspiration, and their cumulative time series at up-, mid-, and downstream is the first step for the four quantitative methods. According to slide $t$-test [16], the year of 1985 was detected as the change point. Figure 2 showed the time series of streamflow, precipitation, and actual and potential evapotranspiration during the whole study period, and the fitted lines for the baseline period and the change period are separated by the year of 1985 .

4.1. Results of Rainfall-Runoff Relationship Method. The relationships between streamflow and precipitation and actual evapotranspiration were established as in Table 1 in the rainfall-runoff relationship method. Three relationship equations at upstream, midstream, and downstream are of great confidence in determining coefficient of $0.96,0.95$, and 0.97 , respectively. Results showed that the contributions of precipitation to runoff at upstream and midstream were $46 \%$ 


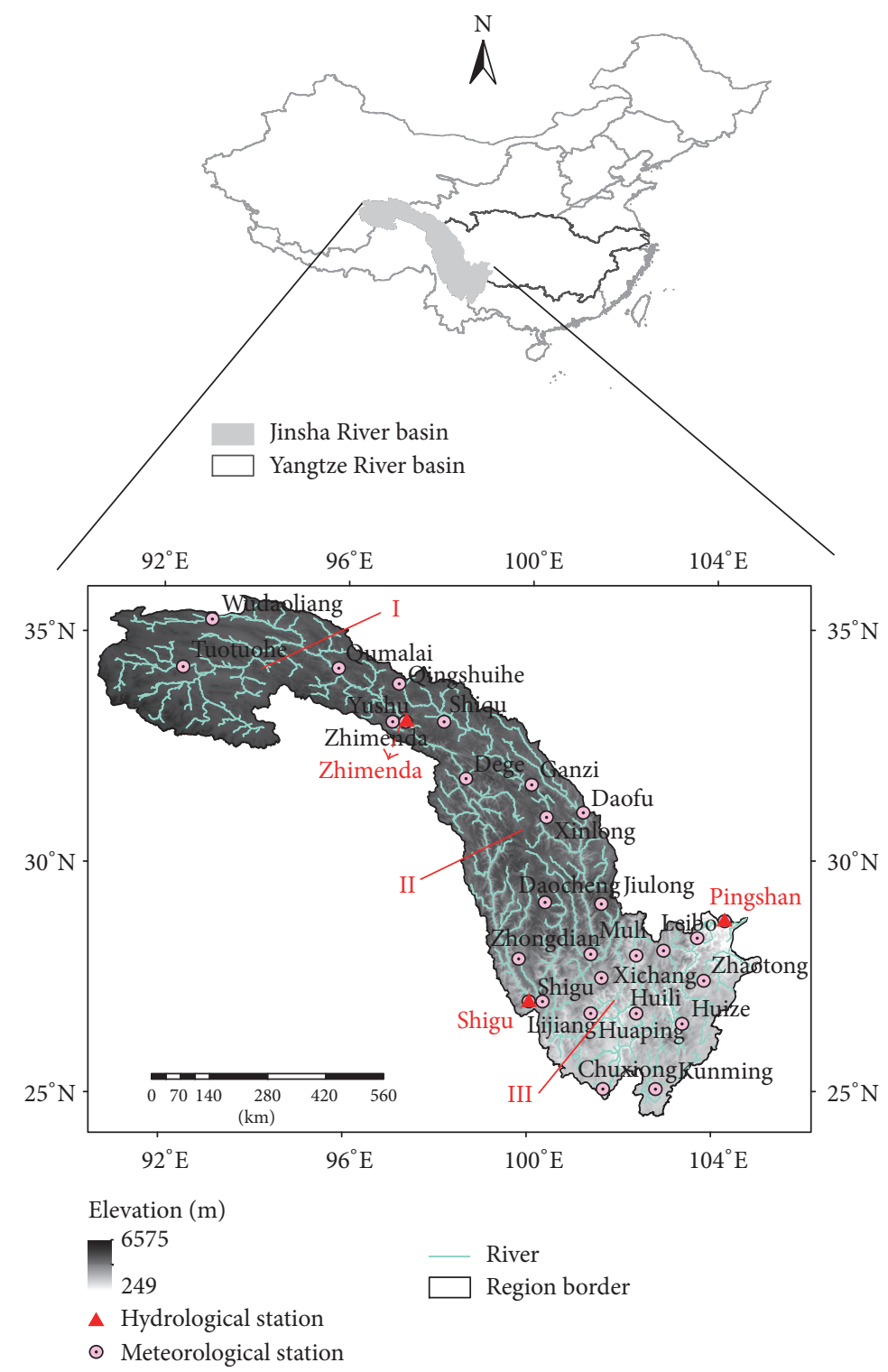

Figure 1: Map of the Jinsha River basin.

and $38 \%$, respectively, and only $12 \%$ at downstream (Table 1 ). The contributions of human activities were $54 \%, 62 \%$, and $88 \%$ at upstream, midstream, and downstream, respectively. Therefore, human activities have more significant impacts on runoff, especially at the downstream.

4.2. Results of Slope Variation Method. The slopes in cumulative runoff, precipitation, and evaporation during the baseline and change periods were calculated as in Table 2 in the slope variation method. In the baseline period, streamflow at upstream, midstream, and downstream decreased and the slope is negative, especially at midstream and downstream. However, streamflow at upstream increased in the change period. Precipitation at midstream and downstream decreased in both periods. Evaporation increased at midstream but decreased at downstream. In the slope variation method, the contribution of climate changes to runoff was $68 \% \sim 69 \%$ at upstream and midstream, but $18 \%$ at downstream (Table 3). Human activities were identified as the largest contributor to runoff at downstream with $82 \%$.

4.3. Results of Double Mass Curve Method. In Figure 3, variations of streamflow, precipitation, and actual and potential evapotranspiration were shown from the baseline period to the change period. The variation of potential evapotranspiration is least in them. For actual evapotranspiration, its variation is largest. Precipitation increased 7\% at midstream, decreased $2 \%$ at upstream, and decreased $12 \%$ at downstream. In the double mass curve method, the contributions of climate changes were $63 \%$ and $53 \%$ at upstream and midstream, respectively (Table 3 ). However, the contribution of climate 


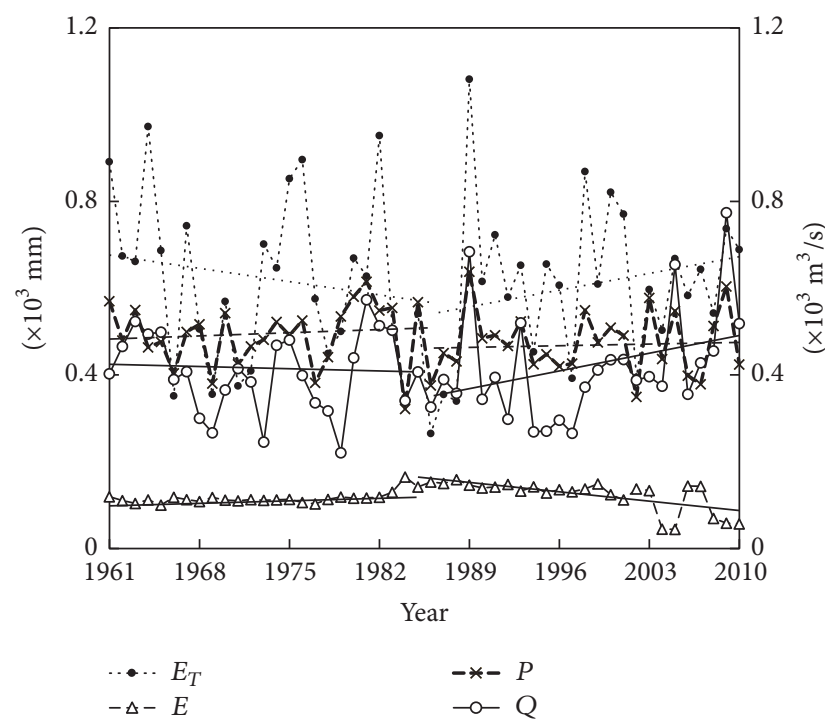

(a) Upstream

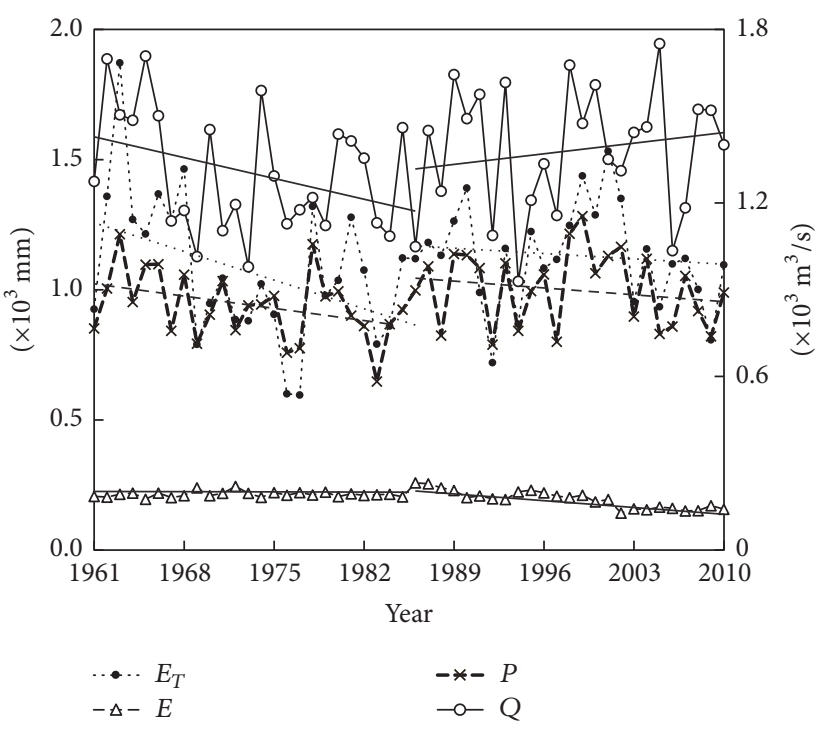

(b) Midstream

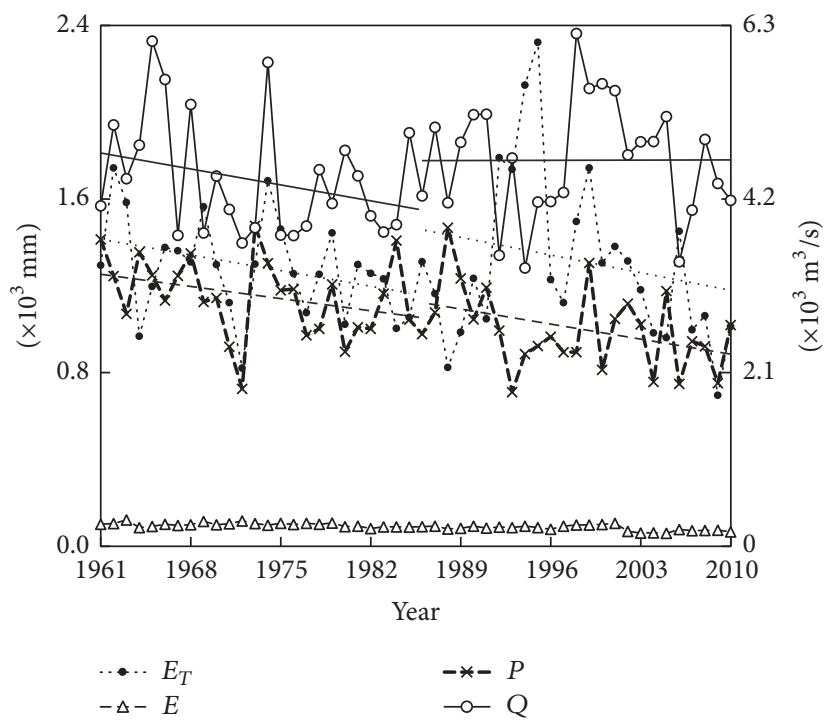

(c) Downstream

FIGURE 2: Streamflow, precipitation, potential and actual evapotranspiration, and their trend-lines at upstream, midstream, and downstream.

TABLE 2: Slope in cumulative runoff, precipitation, and evaporation during the baseline period $(A)$ and change period $(B)$.

\begin{tabular}{lcccccc}
\hline Divisions & & $Q$ & & $P$ & & \\
& $k_{\mathrm{QA}}$ & & $k_{\mathrm{QB}}$ & $k_{P A}$ & $k_{P B}$ & $k_{E A}$ \\
\hline I & -0.05 & & 0.37 & 0.02 & -0.04 & 0.62 \\
II & -0.37 & & 0.04 & -0.31 & -0.16 & 0.06 \\
III & -0.30 & -0.04 & -0.28 & -0.37 & -0.33 & -0.04 \\
\hline
\end{tabular}

Note. $k_{\mathrm{QA}}, k_{\mathrm{QB}}, k_{P A}, k_{P B}, k_{E A}, k_{E B}$ refer to slope of cumulative runoff, precipitation, and evaporation in the baseline period and change period.

TABLE 3: Contributions of climate change and human activities by slope variation, double mass curve, and water balance method.

\begin{tabular}{|c|c|c|c|c|c|c|}
\hline \multirow{2}{*}{ Divisions } & \multicolumn{2}{|c|}{ Slope variation method } & \multicolumn{2}{|c|}{ Double mass curve method } & \multicolumn{2}{|c|}{ Water balance method } \\
\hline & $C$ & $H$ & $C$ & $H$ & $C$ & $H$ \\
\hline $\mathrm{I}$ & $69 \%$ & $31 \%$ & $63 \%$ & $37 \%$ & $72 \%$ & $28 \%$ \\
\hline II & $68 \%$ & $32 \%$ & $53 \%$ & $47 \%$ & $63 \%$ & $37 \%$ \\
\hline III & $18 \%$ & $82 \%$ & $14 \%$ & $86 \%$ & $13 \%$ & $87 \%$ \\
\hline
\end{tabular}

Note. $C$ refers to the contributions of climate changes to runoff, and $H$ refers to the contributions of human activities to runoff. 


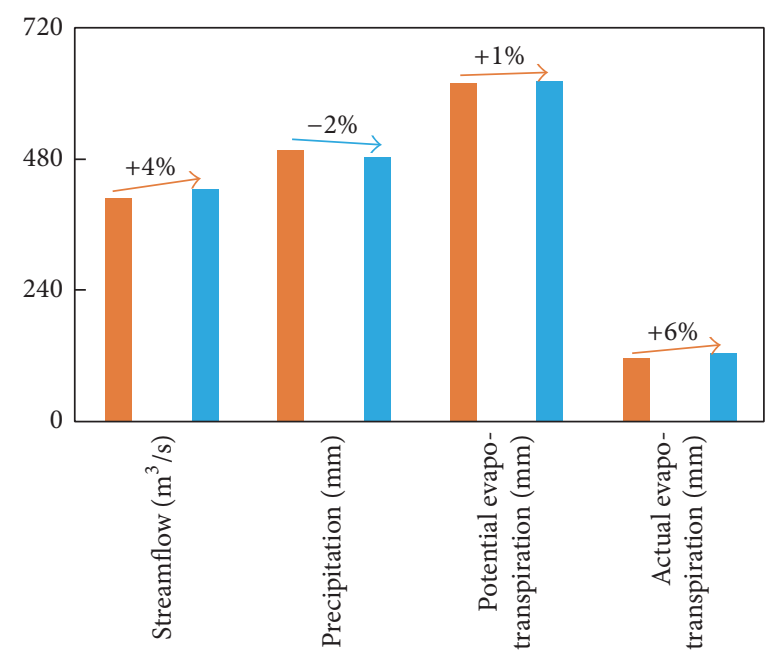

(a) Upstream

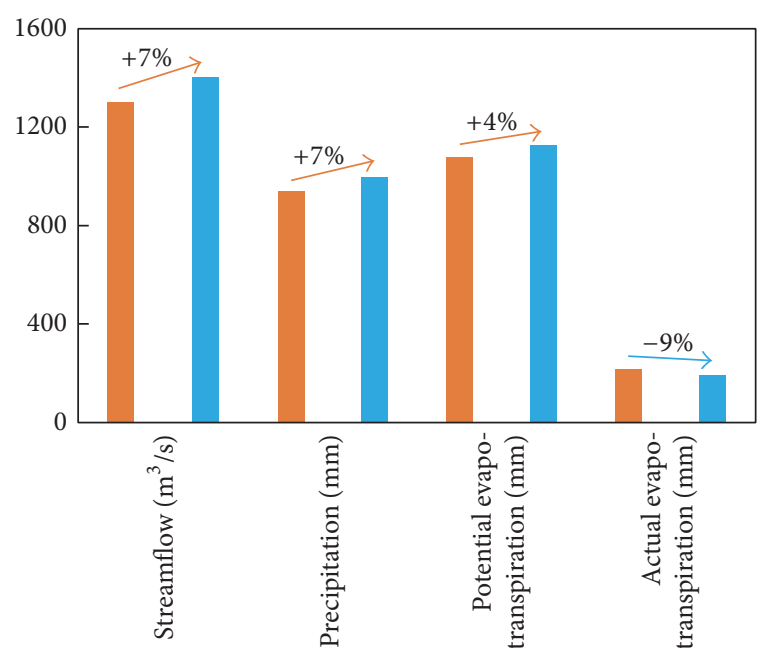

(b) Midstream

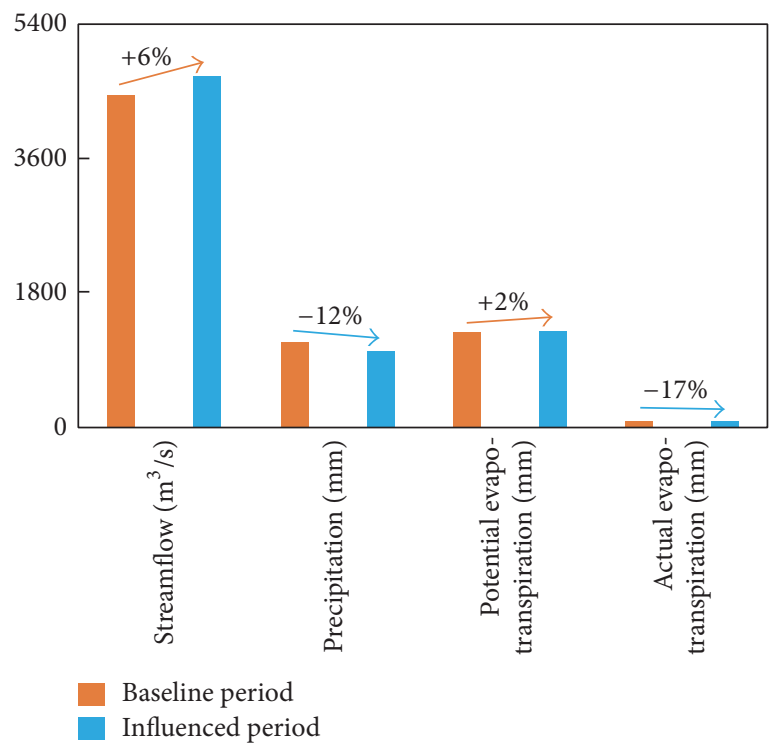

(c) Downstream

FIGURE 3: Variations of streamflow, precipitation, and potential and actual evapotranspiration from the baseline period to the change period at upstream, midstream, and downstream.

changes was $14 \%$ at downstream. These results are of great similarity with the slope variation method.

4.4. Results of Water Balance Method. In the water balance method, contributions of climate changes to runoff were $72 \%$ and $63 \%$ at upstream and midstream, respectively (Table 3 ). Similar to the results obtained by slope variation and double mass curve method, the impact of climate changes was dominant in the runoff at upstream and midstream in the water balance method (Figure 4). At downstream, the impact of human activities was dominant.

\section{Discussion}

The identified change points with discrepancies distribute between 1980 and 1990 by using different methods. The adaptability was analyzed by 11 scenarios in change points for rainfall-runoff relationship, slope variation, and double mass curve method. The results of contribution of climate changes under 11 change points were shown in Figures 5(a)-5(c). Moreover, it illustrates that the contribution of climate changes based on change point in 1985 is centered among results of 11 change points. In addition, all results by different change points only vary within a tiny range in no more than $8 \%$. The largest range of $8 \%$ occurs at upstream in rainfall-runoff relationship method. In the double mass curve method, the contributions of climate changes were $63 \%, 53 \%$, and $14 \%$ at upstream, midstream, and downstream, respectively, for change point in 1985. According to change points from 1980 to 1990 , the contributions at upstream, midstream, and downstream had ranges of $(60 \%, 66 \%),(50 \%$, $56 \%)$ and $(11 \%, 17 \%)$, respectively. 


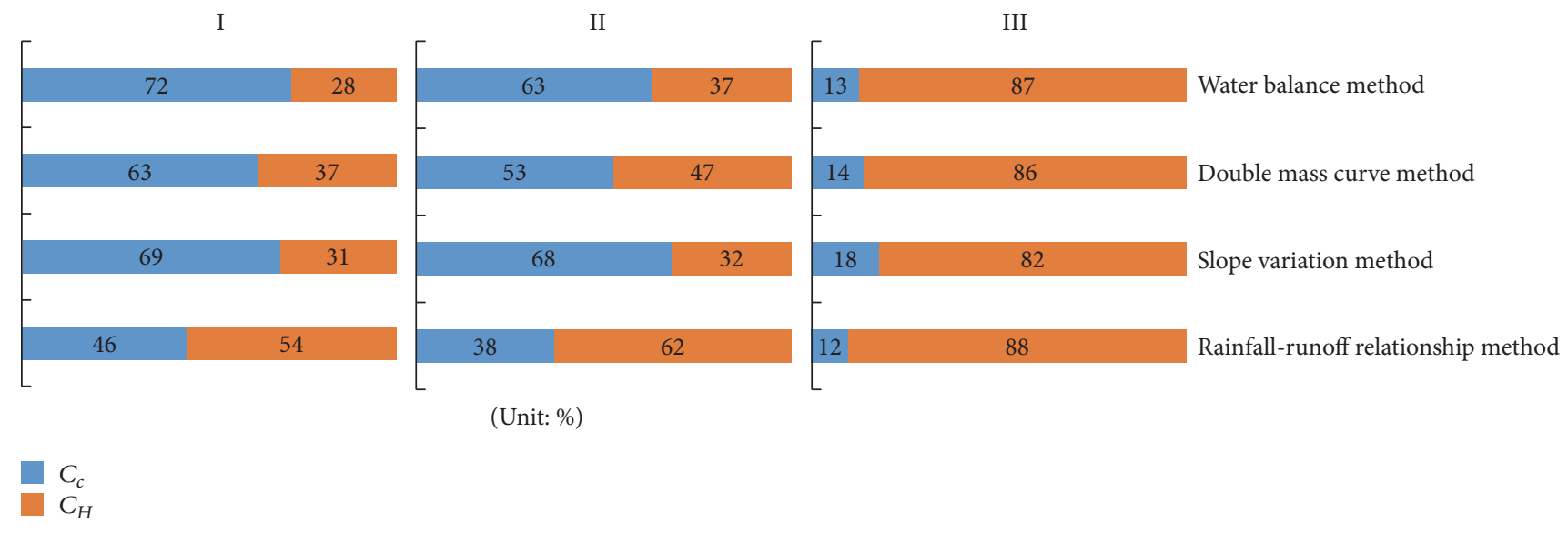

FIGURE 4: Contributions of climate changes and human activities to runoff in the different methods at upstream, midstream, and downstream.

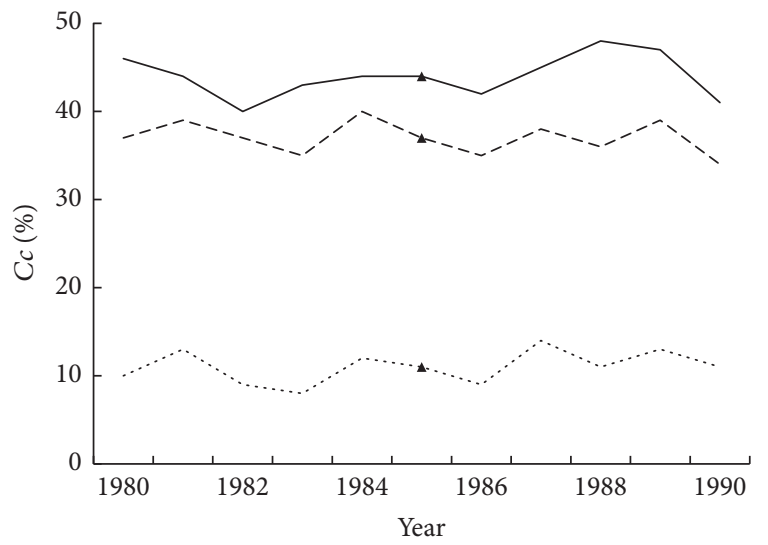

(a) Rainfall-runoff relationship method

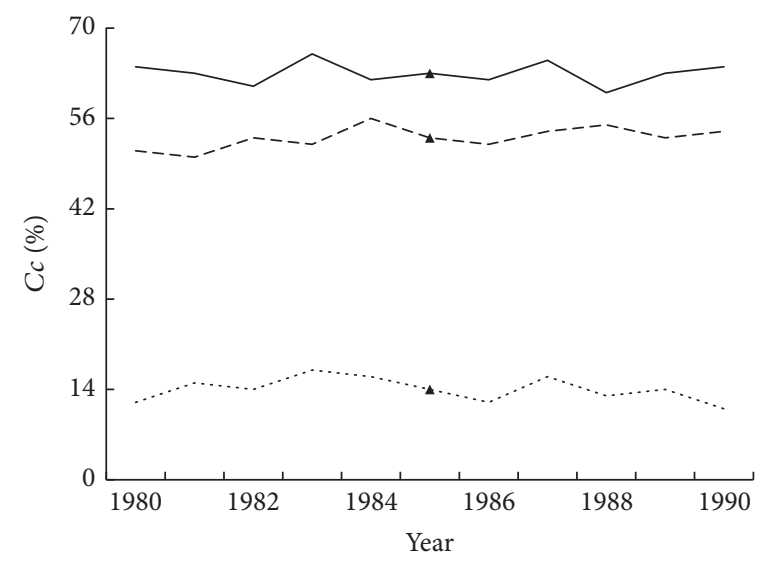

$\begin{array}{ll}- & \text { I } \\ --- & \text { II } \\ \ldots . . & \text { III }\end{array}$

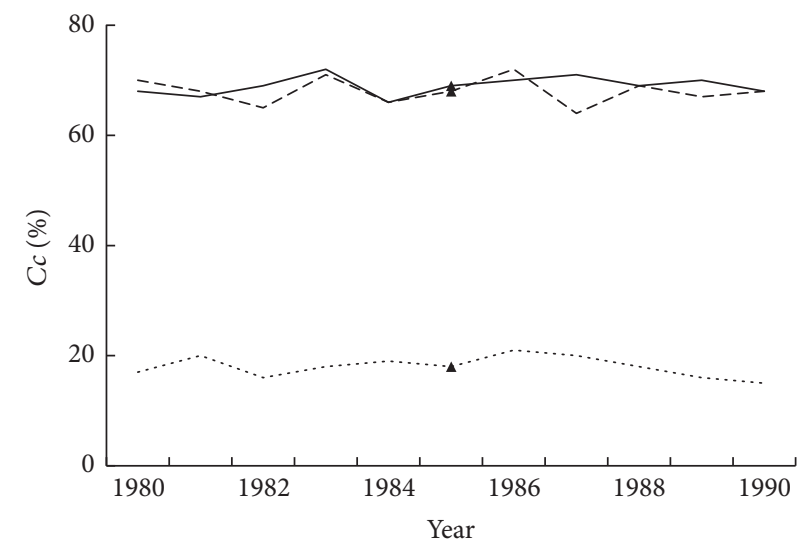

(b) Slope variation method

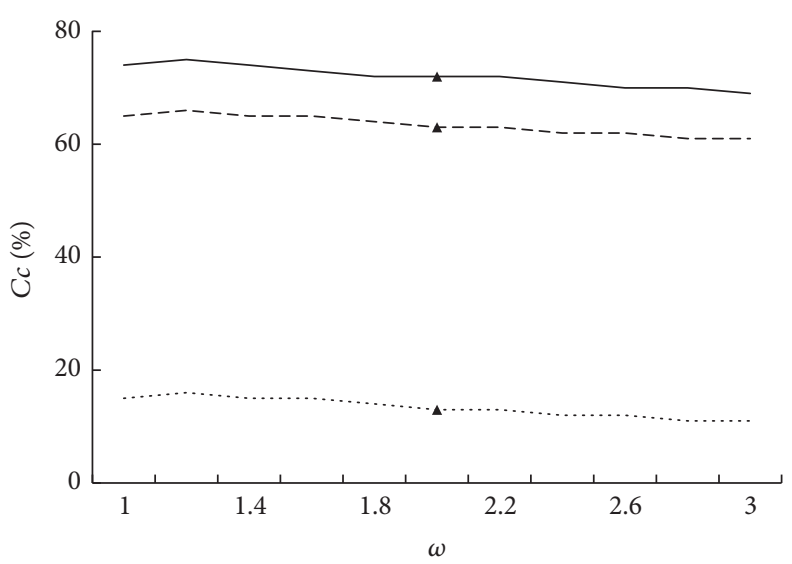

I
--- II
-... III

(c) Double mass curve method

(d) Water balance method

FIGURE 5: Adaptability in rainfall-runoff relationship, slope variation, double mass curve, and sensitivity in water balance method. 
For the water balanced method, parameter $\omega$ was determined by previous studies [29] and there was uncertainty in the parameter. Due to $\omega$ closely related to vegetation and soil conditions, the survey of vegetation was performed. Results showed that $\omega$ was generally in the range of $(1,3)$. Therefore, the scenarios ( $\omega$ varying within $1 \sim 3$ ) were designed for sensitivity of water balance method. In Figure 5(d), the contribution of climate changes to runoff decreased weakly. In sum, results of water balance method are of great consistency with slope variation and double mass curve method.

Except the rainfall-runoff relationship method, the other three methods perform consistently in results (Figure 4). Based on the adaptability in slope variation, double mass curve method, and sensitivity analysis in water balance method, the contributions of climate changes and human activities were determined as the ranges derived from the three methods. At upstream and midstream, the contributions of climate changes to runoff were $63 \% \sim 72 \%$ and $53 \% \sim 68 \%$, respectively. However, the contribution of human activities to runoff was $82 \% \sim 87 \%$ at downstream.

\section{Conclusions}

In the Jinsha River basin, impacts of climate changes and human activities on runoff were analyzed by four quantitative methods, that is, rainfall-runoff relationship, slope variation, double mass curve, and water balance method. The conclusions could be summarized as follows:

(1) Climate changes play a significant role in runoff at upstream and midstream with contributions of $63 \%$ $72 \%$ and $53 \% \sim 68 \%$, respectively.

(2) At downstream, the impact of human activities was dominant in the runoff with contribution of $82 \%$ $87 \%$.

(3) The slope variation, double mass curve, and water balance method perform well in the case study. However, the result of rainfall-runoff relationship method is not satisfactory without consideration of other climate factors, except precipitation.

\section{Conflicts of Interest}

The authors declare that there are no conflicts of interest regarding the publication of this paper.

\section{Acknowledgments}

This study is financially supported by the State Key Program of National Natural Science of China (91647202).

\section{References}

[1] M. J. Esteban-Parra, F. S. Rodrigo, and Y. Castro-Diez, "Spatial and temporal patterns of precipitation in Spain for the period 1880-1992," International Journal of Climatology, vol. 18, no. 14, pp. 1557-1574, 1998.

[2] E. Hertig, S. Seubert, and J. Jacobeit, "Temperature extremes in the Mediterranean area: Trends in the past and assessments for the future," Natural Hazards and Earth System Science, vol. 10, no. 10, pp. 2039-2050, 2010.

[3] F. Viola, A. Francipane, D. Caracciolo, D. Pumo, G. La Loggia, and L. V. Noto, "Co-evolution of hydrological components under climate change scenarios in the Mediterranean area," Science of the Total Environment, vol. 544, pp. 515-524, 2016.

[4] W. H. Schlesinger and C. S. Jones, "The comparative importance of overland runoff and mean annual rainfall to shrub communities of the Mojave Desert," Botanical Gazette, vol. 145, no. 1, pp. 116-124, 1984.

[5] Y. S. Chung and M. B. Yoon, "Interpretation of recent temperature and precipitation trends observed," Theoretical \& Applied Climatology, vol. 67, no. 3-4, pp. 171-180, 2000.

[6] K. Chaouche, L. Neppel, C. Dieulin et al., "Analyses of precipitation, temperature and evapotranspiration in a French Mediterranean region in the context of climate change," Comptes Rendus: Geoscience, vol. 342, no. 3, pp. 234-243, 2010.

[7] D. Pumo, D. Caracciolo, F. Viola, and L. V. Noto, "Climate change effects on the hydrological regime of small non-perennial river basins," Science of the Total Environment, vol. 542, pp. 76-92, 2016.

[8] F. Viola, D. Caracciolo, A. Forestieri, D. Pumo, and L. V. Noto, "Annual runoff assessment in arid and semiarid Mediterranean watersheds under the Budyko's framework," Hydrological Processes, vol. 31, no. 10, pp. 1876-1888, 2017.

[9] C. Prudhomme, D. Jakob, and C. Svensson, "Uncertainty and climate change impact on the flood regime of small UK catchments," Journal of Hydrology, vol. 277, no. 1-2, pp. 1-23, 2003.

[10] C. Prudhomme and H. Davies, "Assessing uncertainties in climate change impact analyses on the river flow regimes in the UK. Part 1: Baseline climate," Climatic Change, vol. 93, no. 1-2, pp. 177-195, 2009.

[11] S. Wang, Z. Zhang, T. R. McVicar, J. Guo, Y. Tang, and A. Yao, "Isolating the impacts of climate change and land use change on decadal streamflow variation: Assessing three complementary approaches," Journal of Hydrology, vol. 507, pp. 63-74, 2013.

[12] D. Caracciolo, L. V. Noto, E. Istanbulluoglu, S. Fatichi, and X. Zhou, "Climate change and Ecotone boundaries: Insights from a cellular automata ecohydrology model in a Mediterranean catchment with topography controlled vegetation patterns," Advances in Water Resources, vol. 73, pp. 159-175, 2014.

[13] C. Jiang, L. Xiong, D. Wang, P. Liu, S. Guo, and C.-Y. Xu, "Separating the impacts of climate change and human activities on runoff using the Budyko-type equations with time-varying parameters," Journal of Hydrology, vol. 522, pp. 326-338, 2015.

[14] L. Liuzzo, L. V. Noto, E. Arnone, D. Caracciolo, and G. La Loggia, "Modifications in Water Resources Availability Under Climate Changes: A Case Study in a Sicilian Basin," Water Resources Management, vol. 29, no. 4, pp. 1117-1135, 2015.

[15] D. Peng, L. Qiu, J. Fang, and Z. Zhang, "Quantification of climate changes and human activities that impact runoff in the Taihu lake Basin, China," Mathematical Problems in Engineering, vol. 2016, Article ID 2194196, 7 pages, 2016.

[16] L. Qiu, D. Peng, Z. Xu, and W. Liu, "Identification of the impacts of climate changes and human activities on runoff in the upper and middle reaches of the Heihe River basin, China," Journal of Water and Climate Change, vol. 7, no. 1, pp. 251-262, 2016.

[17] M. R. Najafi, H. Moradkhani, and I. W. Jung, "Assessing the uncertainties of hydrologic model selection in climate change impact studies," Hydrological Processes, vol. 25, no. 18, pp. 28142826, 2011. 
[18] H. Lauri, H. De Moel, P. J. Ward, T. A. Räsänen, M. Keskinen, and M. Kummu, "Future changes in Mekong River hydrology: Impact of climate change and reservoir operation on discharge," Hydrology and Earth System Sciences, vol. 16, no. 12, pp. 46034619, 2012.

[19] A. Gädeke, H. Hölzel, H. Koch, I. Pohle, and U. Grünewald, "Analysis of uncertainties in the hydrological response of a model-based climate change impact assessment in a subcatchment of the Spree River, Germany," Hydrological Processes, vol. 28, no. 12, pp. 3978-3998, 2014.

[20] Y. Yao, X. Lü, L. Wang, and H. Yu, "A quantitative analysis of climate change impacts on runoff in Naoli River," Advances in Water Science, vol. 21, no. 6, pp. 765-770, 2010.

[21] S. Wang, Y. Yan, M. Yan, and X. Zhao, "Contributions of precipitation and human activities to the runoff change of the Huangfuchuan drainage basin: application of comparative method of the slope changing ratio of cumulative quantity," Acta Geographica Sinica, vol. 67, no. 3, pp. 388-397, 2012.

[22] Z. Hu, L. Wang, Z. Wang, Y. Hong, and H. Zheng, "Quantitative assessment of climate and human impacts on surface water resources in a typical semi-arid watershed in the middle reaches of the yellow river from 1985 to 2006," International Journal of Climatology, vol. 35, no. 1, pp. 97-113, 2015.

[23] C. Jiang, D. Li, Y. Gao, W. Liu, and L. Zhang, "Impact of climate variability and anthropogenic activity on streamflow in the Three Rivers Headwater Region, Tibetan Plateau, China," Theoretical and Applied Climatology, vol. 129, no. 1, pp. 667-681, 2016.

[24] S. Zhou, B. Yu, L. Zhang, Y. Huang, M. Pan, and G. Wang, "A new method to partition climate and catchment effect on the mean annual runoff based on the Budyko complementary relationship," Water Resources Research, vol. 52, no. 9, pp. 71637177, 2016.

[25] R. N. Jones, F. H. S. Chiew, W. C. Boughton, and L. Zhang, "Estimating the sensitivity of mean annual runoff to climate change using selected hydrological models," Advances in Water Resources, vol. 29, no. 10, pp. 1419-1429, 2006.

[26] M. Marchetti, A. Khalifa, and M. Bues, "Methodology to forecast road surface temperature with principal components analysis and partial least-square regression: application to an urban configuration," Advances in Meteorology, vol. 2015, Article ID 562621, 10 pages, 2015.

[27] L. Zhang, K. Hickel, W. R. Dawes, F. H. Chiew, A. W. Western, and P. R. Briggs, "A rational function approach for estimating mean annual evapotranspiration," Water Resources Research, vol. 40, no. 2, pp. 89-97, 2004.

[28] P. C. Milly and K. A. Dunne, "Macroscale water fluxes 2. Water and energy supply control of their interannual variability," Water Resources Research, vol. 38, no. 10, pp. 24-1-24-9, 2002.

[29] C. Liu and D. Zhang, "Temporal and spatial change analysis of the sensitivity of potential evapotranspiration to meteorological influencing factors in China," Acta Geographica Sinica, vol. 66, no. 5, pp. 579-588, 2011.

[30] T. Choi, J. Hong, J. Kim et al., "Turbulent exchange of heat, water vapor, and momentum over a Tibetan prairie by eddy covariance and flux variance measurements," Journal of Geophysical Research D: Atmospheres, vol. 109, no. 21, pp. D21106-12, 2004.

[31] L. J. Li, L. Zhang, H. Wang et al., "Assessing the impact of climate variability and human activities on streamflow from the Wuding River basin in China," Hydrological Processes, vol. 21, no. 25, pp. 3485-3491, 2007. 

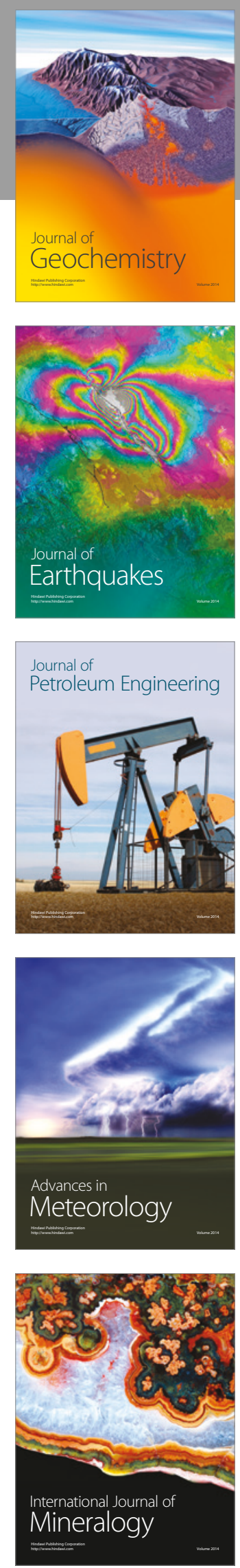
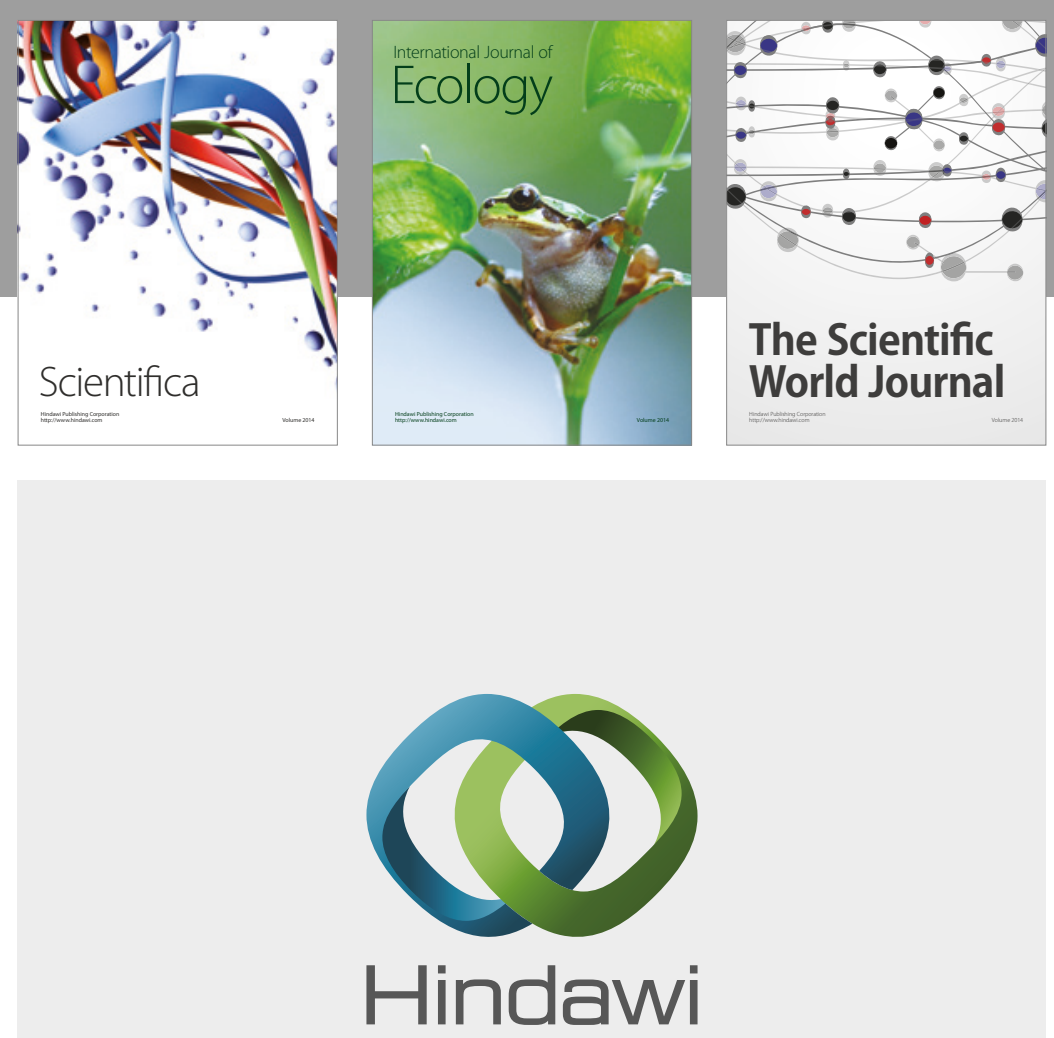

Submit your manuscripts at

https://www.hindawi.com
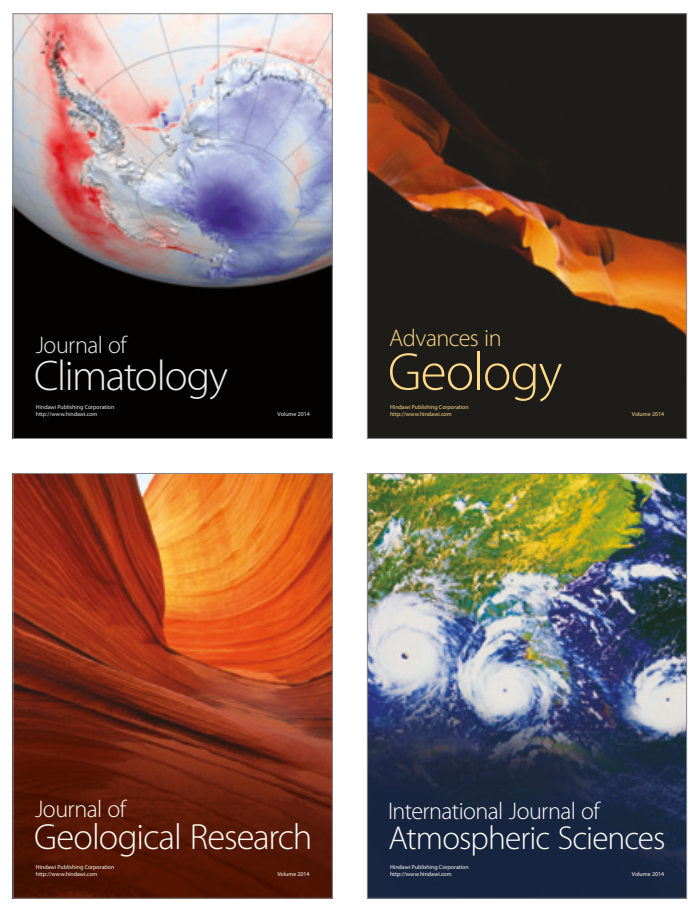

The Scientific

World Journal
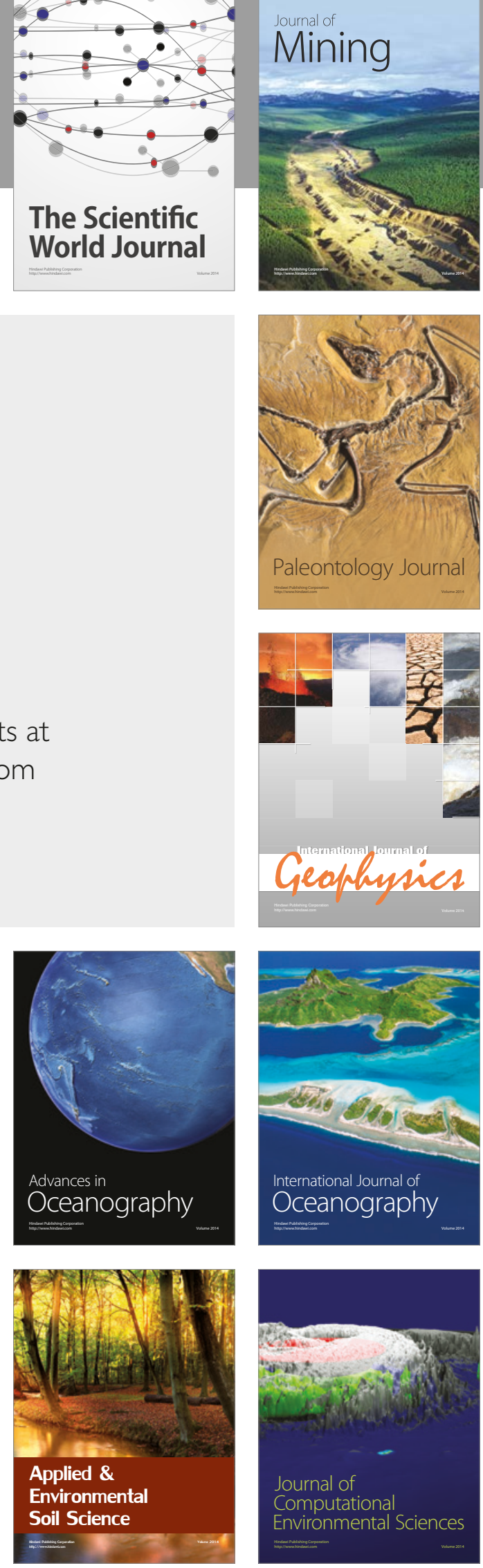